\title{
PESQUISA DE AGLUTININAS ANTI BRUCELLA CANIS EM SOROS HUMANOS NA CIDADE DE SÃO PAULO, BRASIL *
}

\author{
Maria Helena Matiko Akau Larsson **
}

\begin{abstract}
RSPUB9/518
Larsson, M. H. M. A. Pesquisa de aglutininas anti Brucella canis na cidade de São Paulo, Brasil. Rev. Saúde públ., S. Palllo, 14:404-7, 1980.

RESUMO: De 330 soros humanos examinados pela prova de soroaglutinaçāo lenta em tubos, $4(1,21 \%)$ apresentaram aglutininas anti Brucella canis em diluifão 1:100 (1 reagente com título 100, 2 reagentes com título 200 e 1 reagente com titulo 400$)$.
\end{abstract}

UNITERMos: Sorodiagnóstico. Aglutininas. Brucella canis.

\section{INTRODUCQAO}

A brucelose canina é uma doença contagiosa de cães que se caracteriza por comprometimento de tecidos linfóides, aborto e infertilidade (Moore ${ }^{13}$, 1969; Spink ${ }^{15}$, 1970; Spink e Morisset 16, 1970; Meyer 12, 1974 e no Symposium on Immunity... 1s, 1970) e bacteremia prolongada (Spink ${ }^{1 \pi}$, 1970; Van Hoosier Jr. e col.1:1, 1970; Carmichael e George ${ }^{3}, 1976$ ).

O perigo da transmissão da brucelose canina ao homem foi abordado por Faigel 6 (1969), Freemans (1971) e Wooley e col.21 (1976). Embora o único animal que tem apresentado infecção natural por Brucella canis seja o cão, a doença tem potencial zoonótico devido à estreita relação entre esse animal e o homem (Lewis Jr. e Anderson $\left.{ }^{10}, 1973\right)$, fato este que tem sido comprovado através dos relatos de casos humanos de infecção por Brucella canis (Carmichael e col. ${ }^{*}$, 1968; Swenson e col. ${ }^{17}$, 1972; Blankenship e Sanford 2, 1975; Lovejoy e col. $\left.{ }^{11}, 1976\right)$ e também através dos trabalhos de prevalência de aglutininas anti Brucella canis em soros humanos (Lewis Jr. e Anderson 1", 1973; Hoff e Schneider ${ }^{9}, 1975$; Barg e col.', 1977: Weber e Bruner 20, 1977).

Constan da literatura médica vários trabalhos referentes a relatos de casos humanos de doenças por Brucella canis. Carmichael e col.t, 1968 foram os pioneiros a descrever a infecção no homem, em 2 laboratoristas, que se infectaram acidentalmente, trabalhando com amostras de Brucella canis e Swenson e col.17 (1972) descreveram o primeiro caso humano de infecção por Brucella canis adquirido em conseqüência

* Parte da Tese subordinada ao título "Estu to epideniológico da bricelose canina". São Paulo, 1979", apresentada à Comissão de concurso de Doutorado em Saúde Públíca, no Departamento de Epidemiologia da Faculdade de Saúde Pública da USP.

* Do Departamento de Patologia e Clínica Médien da Faculdade de Medicina Veterinária e Zootecnia da USP - Cidare Universitária - 05508 - São Paulo, SP - Brasil. 
LARSSOx, 2I. H. M. A. Pesquisa de aglutininas anti Brucella canis na cidade de São Paulo. Brasil. Rer. Salide públ., S. Paulo. 14:404-7, 1980.

do contacto com animal doente. O paciente envolvido neste caso tratava-se de uma mulher de 23 anos de idade, portadora de doença cardiaca reumática, que apresentava febre, tremores e faringite, cuja hemocultura foi positiva para Brucella canis e cujo titulo aglutinante foi igual a 200 . Através de investigação epidemiológica incriminouse um animal da espécie canina, fêmea, com hemocultura positiva, como sendo a fonte de infecção.

Munford e col. ${ }^{3}$ (1975) relataram outros 2 casos humanos de infecção por Brucella canis em individuos não envolvidos profissionalmente ao risco da infecção e que apresentavam sintomas tais como: febre, calafrius, indisposiçāo e perda de peso. Um outro caso de doença humana por Brucella canis foi relatado por Blankenship e Sanford ${ }^{2}$ (1975) cuja paciente apresentava febre e bacteremia de 4 meses de duração, - ao exame clinico observaram-se ainda linfadenopatia, hépatu e esplenomegalias.

Assim sendo, segundo o Center for Disease Control " (1977), existem relatados na literatura médica, no período de 1967-1974, 16 casos humanos de infecção por Brucella canis.

O presente trabalho tem a finalidade de verificar a ocorrència da infecção por Brucella canis na cidade de São Paulo.

\section{MATERIAL E METODOS}

Trezentos e trinta soros humanos * foram examinados para pesquisa de aglutininas anti Brucella canis. Os soros foram mantidos a $-200^{\circ} \mathrm{C}$ até o momento da execução da prova de soroaglutinação lenta, utilizando-se apenas aqueles sem eridencia de lremólise.

A provia de soroaglutinação lenta foi realizada segundo a técnica preconizada por
Carmichael (1976):*, obedecendo as recomendações a segutir.

Preparaçio do antigeno: o antigeno para método lento foi preparado a partir de culturas de Brucella canis (RM 6-66), com 48-72 horas de crescimento, em garrafas de Roux contendo "Brucella agar". As bactérias eram removidas da superfície do agar pela adição de $25 \mathrm{ml}$ de solução tamponada ( $\mathrm{pH} 7,2$ e $0,15 \mathrm{M})$. A suspensão resultante era filtrada através de seis camadas de gaze e lavada duas vezes com a referida solução tamponada, por meio de centrifugação a 10.000 r.p.m., durante 20 min. Após a segunda lavagem, o sedimento era ressuspenso em aproximadamente $10 \mathrm{ml}$ de citada solução tamponada e mantido em hanhomaria, a $60-62^{\circ} \mathrm{C}$ durante duas horas, obtendo-se, desta forma, antígeno con brucelas mortas. Em seguida adicionava-se à suspensaao, como preservativo $0,01 \%$ de mertiolate. $O$ antigeno concentrado, assim obtido, era armazenado a $4^{\circ} \mathrm{C}$, até o momento do uso. Para a realização da prova, o antígeno era diluido de forma a obter-se densidade de 0,2 , em comprimento de onda de $420 \mathrm{~nm}$, em espectofotometro Coleman Jr. II, modelo $6 / 20$.

O procedimento para execução da prova de soroaglutinação lenta foi o seguinte:

a) tubos de ensaio $12 \times 75 \mathrm{~mm}$ eram numerados de 1 a 7 ;

b) com uma pipeta de $0,1 \mathrm{ml}$, colocavam-se $0,04,0,02,0,01$ e $0,005 \mathrm{ml}$ de soro. respectivamente, nos tubos $1,2,3$ e 4 .

A seguir, preparava-se uma solução diluida de soro $(1: 10)$, em solução tamponada $(\mathrm{pH} 7,2$ e $0,15 \mathrm{M})$ que era colocada nas quantidades de $0,08,0,04 \mathrm{e}$ $0,02 \mathrm{ml}$, respectivamente, nos tubos 5 , ò e 7 ;

c) para obtenção das diluições 1:50, $1: 100, \quad 1: 200,1: 250, \quad 1: 400, \quad 1: 500$ e $1: 1.000$, adicionavan-se, a cada tubo,

Cedidos pelo Laboratório Clinico do Centro de Saude "Geraldo de Paula Souza" da Faculdade de saúde Pública da USP.

Standard tuhe agglutination test protocol for Brucellu canis diagnosis. 1976. Dados inéditos. 
LARSSON, M. H. M. A. Pesquisa de aglutininas anti Bricella canis na cidade de São Paulo. Brasil. Rev. Saúde públ., S. Paulo. 14:404-7. 1980.

$2 \mathrm{ml}$ de antigeno diluido: a seguir, os tubos eram incubados a $50-52^{\circ} \mathrm{C}$ durante $48 \mathrm{~h}$;

d) em todos os casos realizavam-se duas leituras, sendo a primeira após $24 \mathrm{~h}$ de incubação e a segunda após $48 \mathrm{~h}$ de incubação. Os resultados eram avaliados comparando-se o grau de turvação nos tubos, contendo soro desconhecido com o observado naquele contendo soro controle. Consideravam-se positivos os soros em cujos tubos não havia turvação e sim depósito, indicando aglutinação e, portanto, formação de complexo antígeno-anticorpo; consideravam-se negativos os soros cujos tubos permaneciam com turvação, após 48 horas de incubação;

e) consideravam-se com titulus significativos os soros que se revelavam positivos às provas de aglutinação quando diluídos a $1 / 200$ ou mais.

\section{RESULTADOS}

Dos trezentos e trinta soros humanos examinados pela prova de soroaglutinação lenta, quatro foram positivos para Brucella canis, dos quais um com título $1: 100$, dois $\mathrm{com}$ título 1:200 e um com título $1: 400$.

\section{DISCUSSÃO}

Dentre os trabalhos relativos à prevalência de aglutininas anti Brucella canis em soros humanos, podem-se citar os de: Hoft e Schneider ${ }^{9}$ (1975) que encontraram 3 $(0,99 \%)$ reagentes com titulo $\geqslant 1: 200$, de un total de 303 amostras examinadas;
Lewis e Anderson "19 (1973) que, examinando 1208 soros de recrutas militares norteamericanos, através da prova de soroaglutinação lenta, encontraram uma percentagem de soropositividade de 0,41 , considerando positivos aqueles soros reagentes em diluiçōes $\geqslant 1: 100$; Flores-Castro e Segura' (1976) dentre 203 soros humanos examinados observaram $27 \mathrm{com}$ titulo $\geqslant 1: 100$, ou seja, 13,3\% positivos; Barg e col.' (1977) observaram uma prevalência de $0,81 \%$ de reagentes para anticorpos anti Brucella canis de um total de 2020 soros humanos (doadores de sangue); Weber $t$ Bruner :o (1977) dentre 1915 soros humanos detectaram anticorpos aglutinantes contra Brucella canis em 6 amostras $(0,31 \%)$ através do teste de soroaglutinação lenta.

Ainda é verdadeira a hipótese de que o, homen pode, realmente, se infectar com o agente do aborto canino, conforme se denota pelos casos descritos na literatura (Carmichael e col.t, 1968; Swenson e col.ri. 1972; Munford e col.14, 1975; Blankenship e Sanford ", 1975; Lovejoy e col. ${ }^{11}, 1976$ ). Sendo assim, deve-se pensar na possibilidade de infecção humana por Brucella canis nos casos em que ocorrem comprometimento de tecidos linfóides e hipertermia de etiologias indeterminadas.

\section{CONCLUSOES}

Através da metodologia empregada neste trabalho, os resultados permitem concluir que a prevalência da infecção humana por Brucella canis, avaliada pela pesquisa de aglutininas especificas, foi realizada pela primeira vez em São Paulo, encontrando-se resultado igual a $1,21 \%$. 
LARSSON, M. H. M. A. Pesquisa de aglutininas anti Brucella canis na cidade de Sao Paulo, Brasil. Rev. Saude puibl., S. Paulo, 14:404-7, 1980.

RSPUB9/517

LARSSON, M. H. M. A. IResearch on agglutinins for Brucella canis in human sera in the city of S. Paulo, Brazil.J Rev. Saúde públ., S. Paulo, 14: 404-7,

ABSTRACT: Of the 330 human sera tested by tube agglutination test, 4 $(1.21 \%)$ were positive for Brucella canis antibodies with titers 1:100 or higher (1 reagent with titer of $1: 100,2$ reagents with titer of $1: 200$, and 1 reagent with titer of $1: 400)$.

UnITERMS: Serodiagnosis. Agglutinins. Brucella canis.

\section{REFERENCIAS BIBLIOGRAFICAS}

1. BARG, L. et al. Pesquisa de aglutininas anti Brucella canis em soros himanos. Arq. Esc. Vet. UFMG, $29: 31-4,1977$.

2. BLANKENSHIP, R. M. \& SANDFORD, J. P. Brucella canis: a case of undulant fever. Amer. J. Med., 59:424-6, 1975.

3. CARMICHAEL, L. E. \& GEORGE, L. W. Canine brucellosis: newer knowledge. International Symposium on Bruceilosis (II), Rabat, 1975. Develop. biol. Stand., $31: 237-50,1976$.

4. CARMICHAEL, L. E. et al. Human infection with the agent of canine abortion. Bol. inf. trimest. Centro $P a$ namer. Zoon., 10:24-7, 1968.

5. CENTER FOR DISEASE CONTROL. Brucellosis in the United States, 1965-1974. $J$. infect. Dis., 136:312-6, 1977.

6. FAIGEL, H. C. Beagle fever-canine brucellosis. Clin. Pediatr., 8:59, 1969.

7. FLORES-CASTRO, R. \& SEGURA, R. A serological and bacteriological survey of canine brucellosis in Mexico. Cornell Vet., 66:347-52, 1976.

8. FREEMAN, A. Canine brucellosis. $J$. Amer. vet. med. Ass., 159: 6-7, 1971.

9. HOFF, G. L, \& SCHNEIDER, N. J. Serologic survey for agglutinins to Brucella canis in Florida resi lents. Amer. $J$. trop. Med. Hyg., 24:157-9, 1975.

10. LEWIS JR., G. E. \& ANDERSON, J. K. The incidence of Brucella canis antibodies in sera of military recruits. Amer. J. publ. Hlth, 63:204-5, 1973.

11. LOVEJOY, G. S. et al. Serosurvey of dogs for Brucella canis infection in $\mathrm{Mem}$ phis, Tennessee. Amer. J, publ. Elth, $66: 175-6,1976$.
12. MEYER, M. E. Advances in research on br: cellosis, 1957-1972. Adv. vet. Soi. comp. Med., 18:231.50, 1974.

13. MOORE, J. A. Brucella canis infection in dogs. J. Amer. vet. med. Ass, 155: 2034-7, 1969.

14. MUNFORD, $R$. $S$. et al. Human disease caused by Brucella canis. A clinical and epidemiologic study of two cases. J. Amer, med. Ass., 231:1267-9, 1975.

15. SPINK, W. W. Comments on canine brucellosis due to Brucella canis. J. Amer. vet. med. Ass., 156:1734-6, 1970.

16. SPINK, W. W. \& MORISSET, R. Epidemic canine brucellosis due to a new species: $B$. canis. Trans. Amer. clin. climat. Ass., 81:43-50, 1970.

17. SWENSON, R. M. et al. Human infection with Brucella canis. Ann. intern. Med., $76: 435 \cdot 8,1972$.

18. SYMPOSIUM ON IMMUNITY TO SELECTED CANINE INFECTIOUS DISEASES, New York, 1969. Report of the panel. J. Amer. vet, med. Ass., 156: 1661-8, 1970.

19. VAN HOOSIER JR, G. L. et al. Enzootic abortion in a canine colony. III. Bacteremia, antibody response and mercaptoethanol sensitivity of agglutinins in naturally infected dogs $1,2,3$. Lab. anim. Care, 20:964 8, 1970.

20. WEBER, A. \& BRUNER, H. Seroepidemiologisch intersuchungen zum Vorkommeen von Antikörpern gegen Brucella canis bein Menschen. Zbl. Bakt. Hyg. I. Abt. Orig. A., 238:237-43, 1977.

21. WOOLEY, R. E. et al. Canine brucellosis in man. Mod. vet. Pract., 57:287-90, 1976.

Recebido para publicaৎăo em 19/03/1980 Aprovado para publicacão em 23/06/1980 